\title{
Аларен колапс
}

\author{
Пл. Недев \\ Клиника по УНГ-болести при \\ УМБАЛ „Св.Марина“ - Варна, МУ - Варна, ФДМ
}

Резюме

Ние представяме нашия опит при реконструкция на външна носна клапа при вродени и придобити състояния на аларен колапс, включително случаи на колапс следствие септопластика и ринопластики. Лечението е преди всичко хирургично - имплантиране на хрущял, провеждане на латерална ринопексия или сутурни техники.

Ключови думи: аларен колапс, хрущялна присадка, латерална ринопексия.

\section{Abstract \\ We present our experience of reconstruction of the external nasal valve after congenital and iatrogenic collapse, included collapses that followed septoplasty for septal deviation, reconstructions, and rhinoplasties. Permanent treatment for external nasal valve col- lapse is primarily surgical - the placement of structural alar rim grafts or lateral rhinopexy and suturing techniques.}

Keywords: allar collapse, cartilage graft, laterals rhinopexy.

\section{Увод}

Аларният колапс се среща относително рядко, като причина за затруднено носно дишане. Това състояние може да бъде вродено или придобито. Вроденият аларен колапс е често срещан при т. нар. „заешка уста“ или при отворено небце. Придобито състояние е обикновено вследствие на травма, включително ятрогенно обусловен. Симптомите са от естетично и функционално естество. Функционалните нарушения са видими при вдишване - носните крила колабират (особено при повишени физически натоварвания) и обтурират напълно или частично входа на носа.

Цел на публикацията е да представим литературен обзор на използваните хирургични техники и нашия опит при оперативното лечение на аларния колапс.

\section{Материал и методи}

За десетгодишен период (2000 - 2010 г.) по повод аларен колапс са оперирани 37 пациенти. При 22 от тях причината за състоянието е ятрогенна (18 след ринопластика и 4 след септопластика), а при 15 състоянието бе вродено (заешка устна и/или отворено твърдо небце). Едностранна патология срещнахме при 4, а при останалите 33 аларният колапс бе двустранен. Оперативните техники, които приложихме, са:

1. Латерална ринопексия

2. Имплантиране на собствен хрущял

3. Модифицирана латерална ринопексия

4. Фиксиране на краниалния край на аларния към каудалния край на триангуларните хрущяли.

5. Сутурни техники 
При 22 от пациентите приложихме външен, а при 15 - ендоназален достьп. От всички оперирани 32 бяха с деформитети на носната преграда, което наложи септопластика, а при 5 самостоятелни.

\section{Резултати и обсъждане}

Според изследванията на Lang (1) медиалните крачета и крилата на аларните хрущяли сключват ьгъл средно $54^{\circ}\left(38-86^{\circ}\right)$, а крилата на аларните хрущяли припокриват триангуларния хрущял средно с 2,9 мм (1 - 4 мм) (Фиг. 1.). Това осигурява подпо-

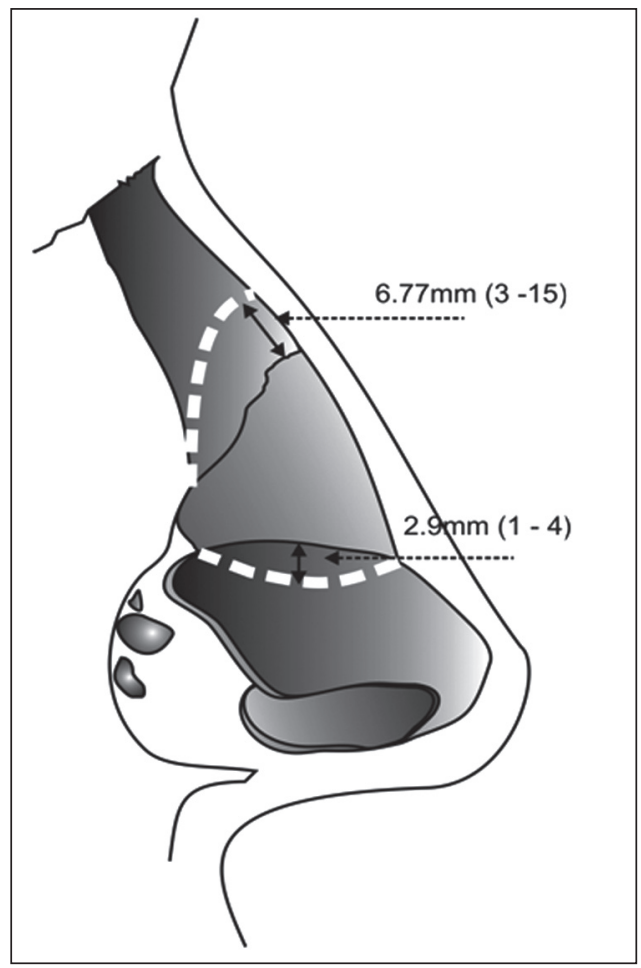

Фиг. 1. Размери на припокриване на триангуларните от аларните хрущяли и преминаване на триангуларните хрущяли под носните кости. Ъгъљт между медиалните крачета и крилото на аларния хрущял - средно $54^{\circ}\left(38-86^{\circ}\right)$

ра на носните крила и тяхното дозирано движение при инспириум. При това аларните хрущяли са с превенция от колапс и благодарение на мускулите на външния нос, както и от съединително-тъканни връзки. Нарушения на тази архитектоника (вродени или придобити, вкл. ятрогенни) водят до хльтване на носните крила към медиалната носна стена при вдишване спонтанно и особено при екстремни физически изисквания. Аларният колапс може да бъде самостоятелно състояние, но може да бъде комбинирано с девиация на носната преграда и недостатъчност на вътрешната носна клапа на Mink. Оперативните техники за корекция на вътрешната носна клапа са разработеви в дисертационния труд на Р. Бенчев (2) .
Затрудненото носно дишане, причинено от аларен колапс, е сериозен терапевтичен проблем. Консервативното лечение се състои в прилагането на специални уреди, поставени във входа на носа (3), (4), които осигуряват нормално дишане по време на сън (фиг. 2).

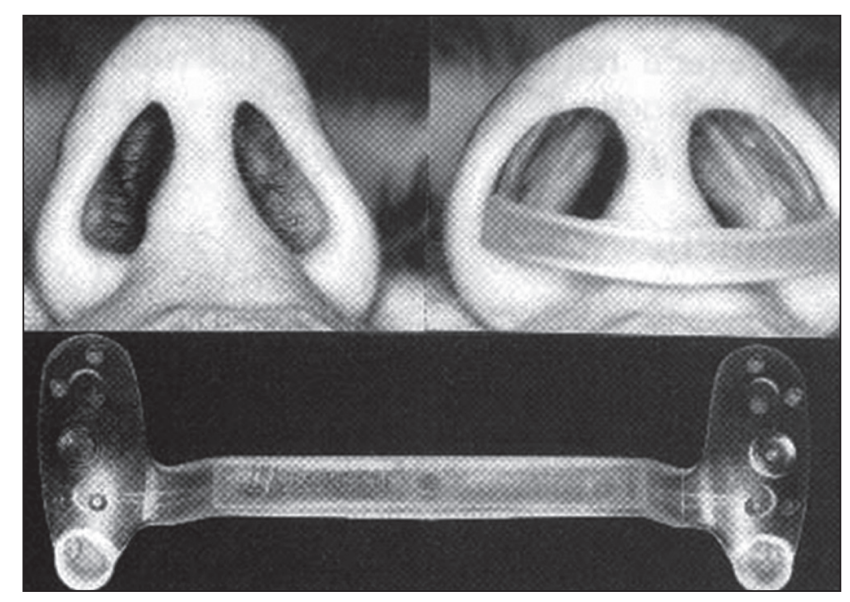

Фиг. 2. Силиконова протеза за входа на носа, осигуряваща носно дишане. Начин на поставяне на устройството.

Метод на избор е хирургичното лечение. Целта е да се фиксират или стабилизират крилата на аларните хрущяли посредством имплантиране на допълнителен хрущял, ринопексия или различни сутурни техники (5) (Фиг. 3)

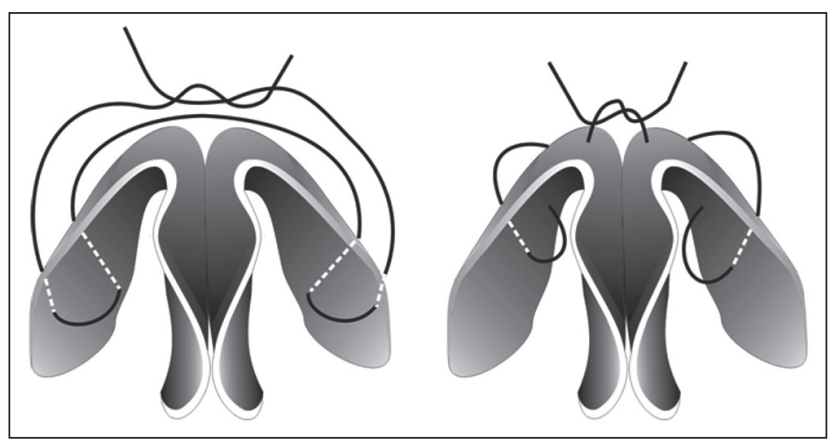

Фиг. 3. Сутурни техники за отдалечаване и фриксиране на носните крила

През 1992 г. Goode RL (6), Gunter JP и Rohrich RJ (7) за първи път прилагат имплантиране на хрущял върху носните крила с цел те да бъдат укрепени. Имплантацията е върху аларните хрущяли (overlay) или под тях (underlay), като за опора се използва костният край на aperture piriformis (8) (Фиг. 4). Същите автори описват и метод на поддръжка на аларните и триангуларните хрущяли едновременно. „Butterfly graft“ (присадка под формата на пеперуда) е имплантиране на хрущял, укрепващ седловидно придобит нос, но в същото време би могла да се съчетае с укрепване и на аларния колапс (9) (фиг. 5). 


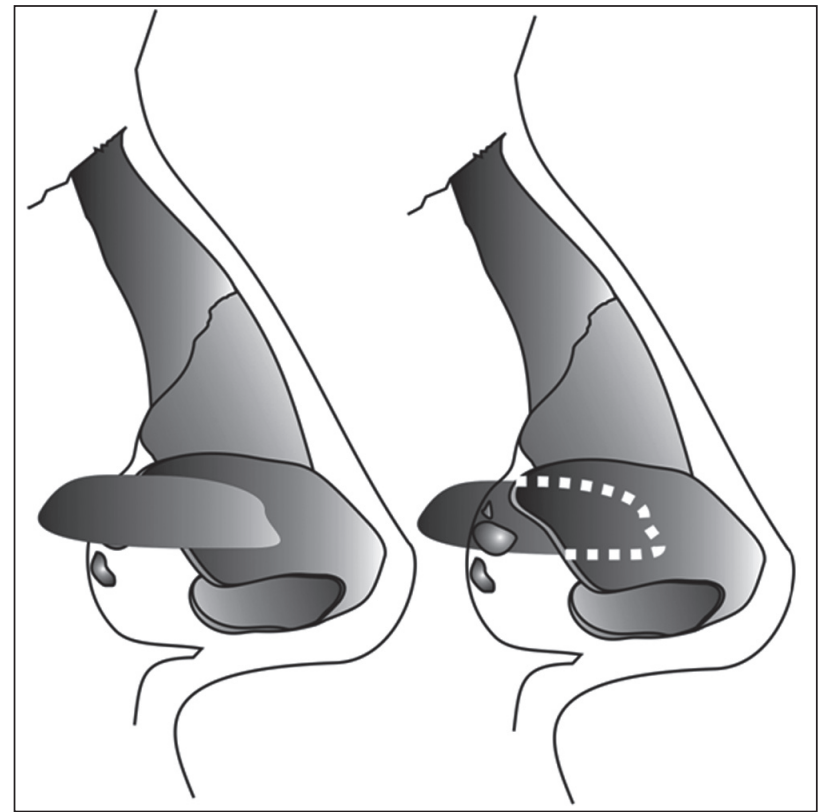

Фиг. 4. Начини на поставяне на хрущялната присадка - над или под крилата на аларните хрущяли

Латерална ринопексия е метод, целящ преместване и фиксиране на носните крила върху apertura pyriformis (10), (11) (Фиг. 6.)

Ние приложихме и техника, с която аларното крило се фиксира за триангуларния хрущял - пришиване на аларния хрущял върху триангуларния (Фиг. 7). При два от случаите извършихме „Перкутанна фиксация на носните крила“ (фиг. 8 и фиг. 9).

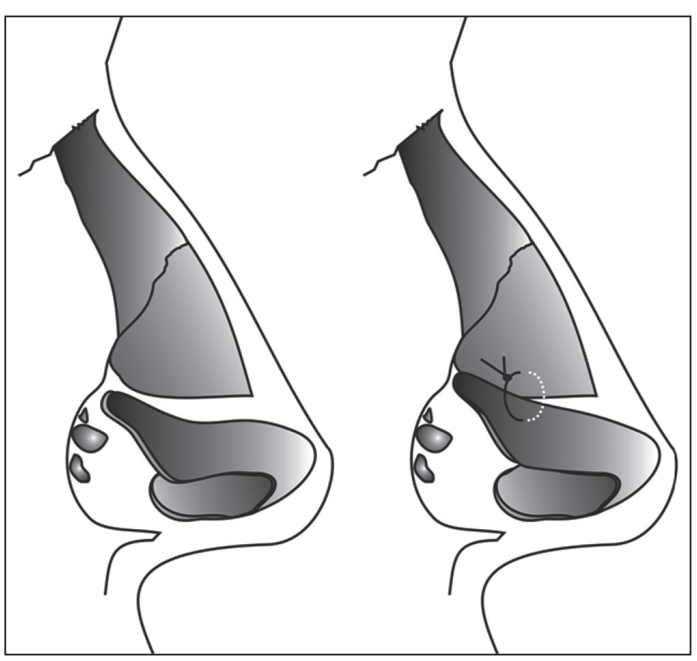

Фиг. 7. Фиксиране на аларния към триангуларния хрущял със сутури

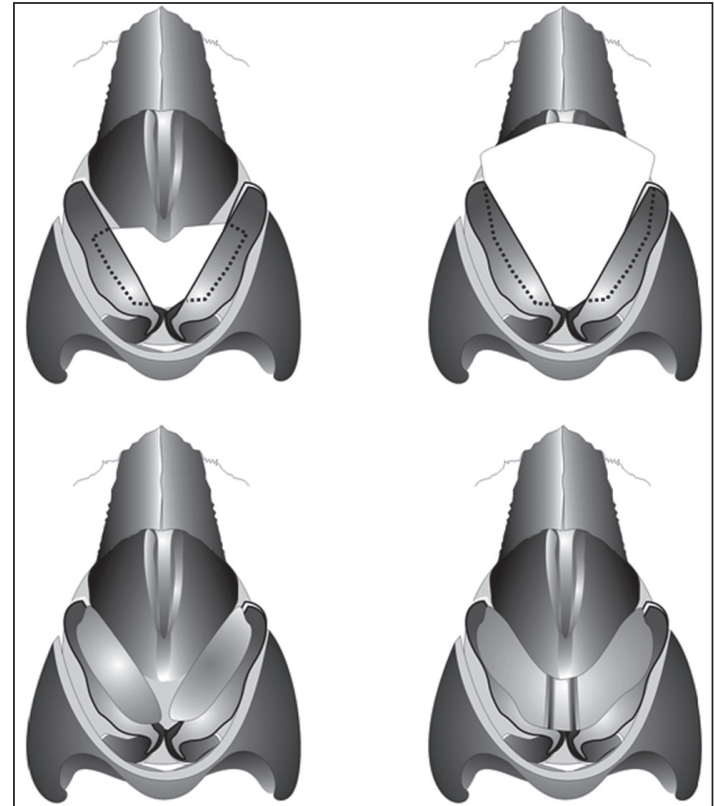

Фиг. 5. Начини на едновременно укрепване на аларните и триангуларните хрущяли

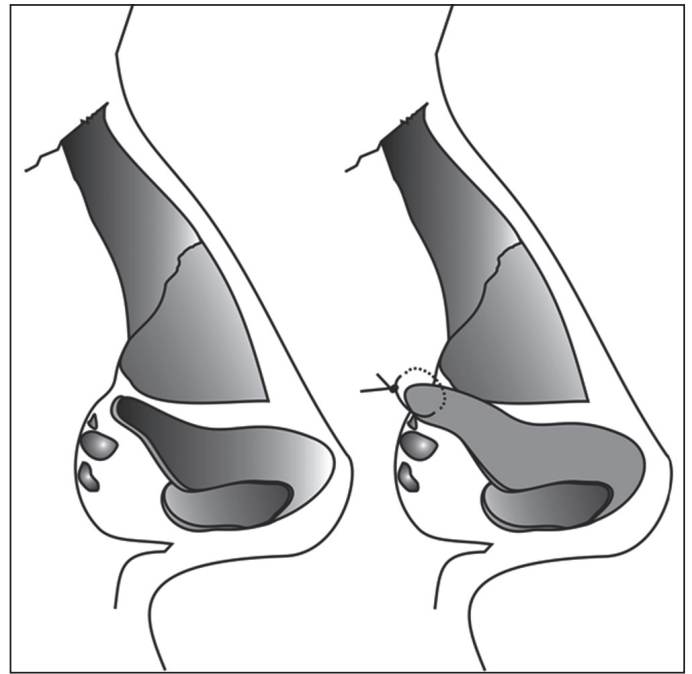

Фиг. 6. Латерална ринопексия

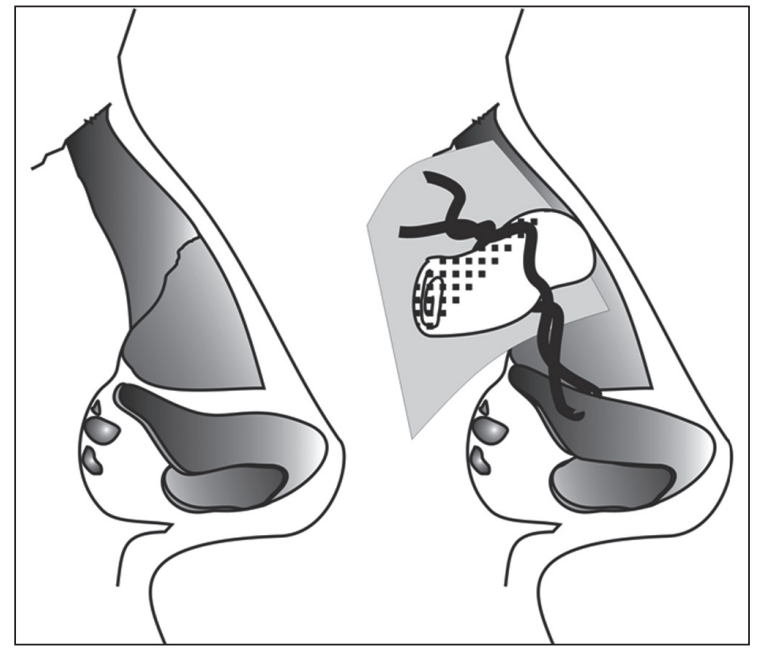

Фиг. 8. Перкутанна фриксация на аларните хрущяли и фиксиране 


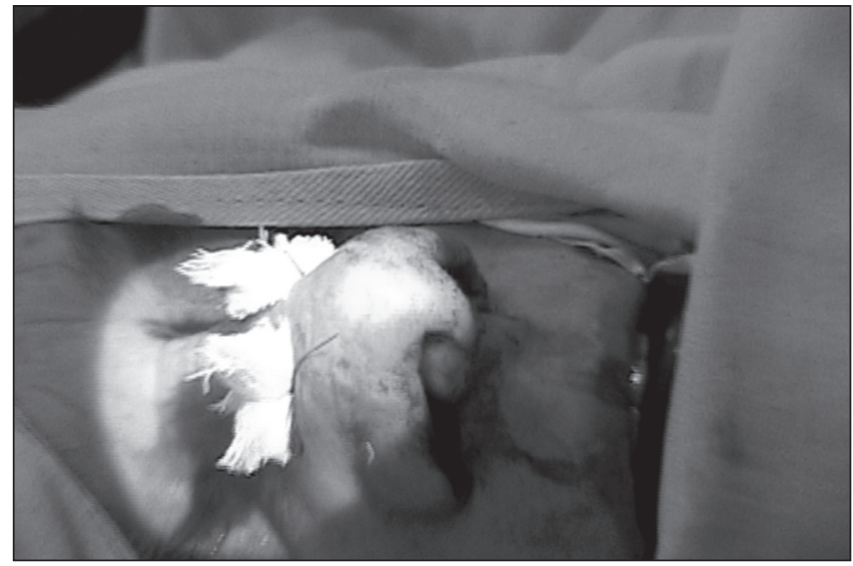

Фиг. 9. Пексия на аларните хрущяли и фриксиране върху гърба на носа

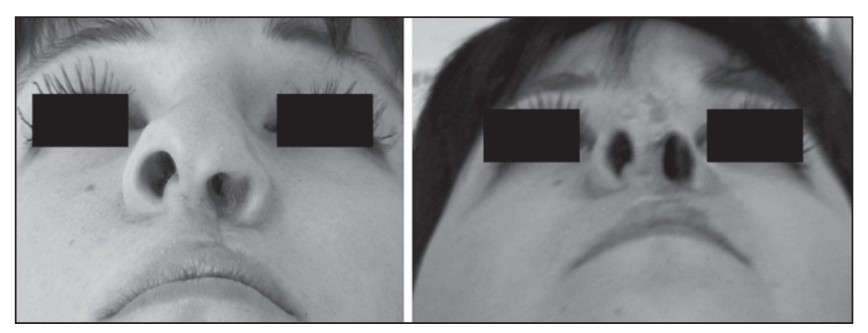

Фиг. 11. Вроден аларен колапс.

Сутурна техника преди и след операцията (ранен следоперативен резултат)

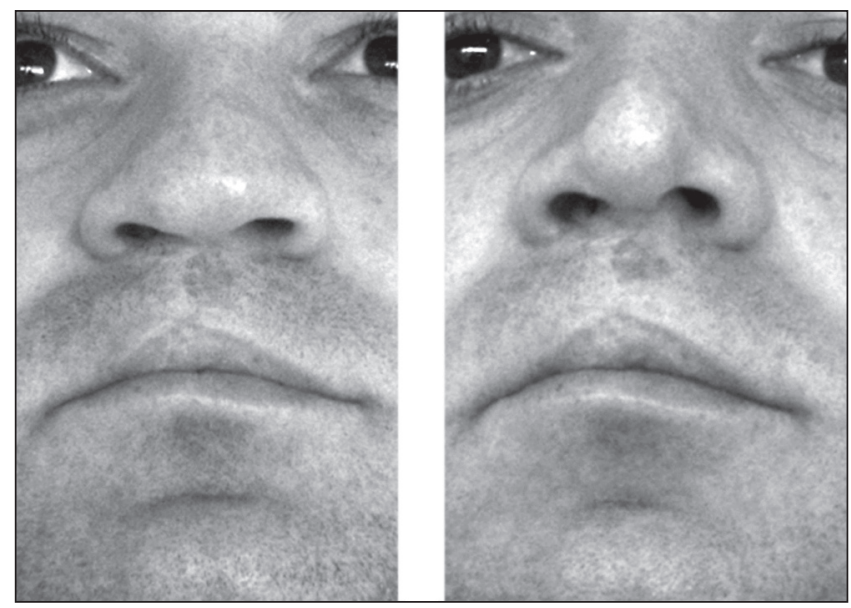

Фиг. 13. Вроден аларен колапс. Късен оперативен резултат след латерална ринопексия и имплантация на хрущял.

Резултатите на тези оперирани бяха с краткотраен ефект и два месеца по-късно се отчете рецидив. Постоянни и добри резултати във функционално и естетично отношение постигнахме при латералната ринопексия, трансплантация на хрущял и при сутурните техники.

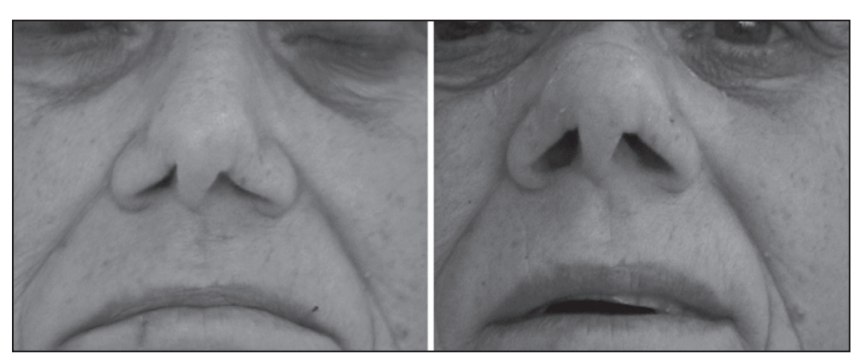

Фиг. 10. Късен резултат при пациентка след ятрогенна аларна недостатъчност и „перкутанна фриксация на носните крила“

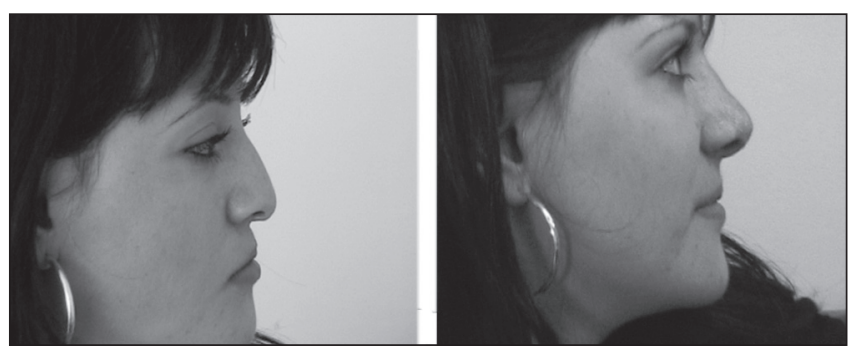

Фиг. 12. Вроден аларен колапс.

Сутурна техника преди и след операцията (ранен следоперативен резултат)

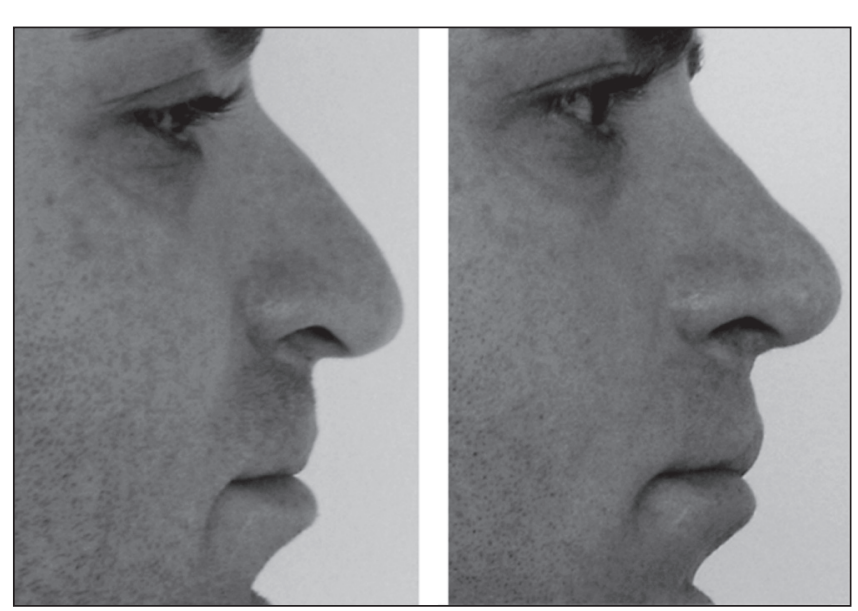

Фиг. 14. Същият пациент в профрил

\section{Заключение и изводи}

1. Най-честата причина за аларна недостатъчност е травматична (вкл. ятрогенна - след риносептопластика, или субмукозна резекция по метода на Killian).

2. Аларният колапс е труден за решение хирургичен проблем. 
3. Владеенето на различни хирургични техники е ключ към решението на проблема.

4. Според нашите наблюдения по-ефективни са агресивните методики - външен достьп, лате-

\section{Литература}

1. Lang J. Kliniche Anatomie der Nase, Nasenholen und Nebenholen: Grundlagen fur Diagnostik und Operation. 1988, Stuttdart; New York: Thieme. 1-134.

2. Бенчев, Р. Дисфункция на носната клапа - причини, диагностика и възможности за хирургично лечение Дис. София 2005.

3. Милков М. Клинично обусловени нарушения на съня. Международен бюлетин по оториноларингология. 2009, 4, 37-41.

4. Милков М, П. Недев, Л. Матев, Ц. Тончев, И. Ценев. Лечение на съннообусловените нарушения на дишането чрез ендоназални и интраорални апарати. Международен бюлетин по оториноларингология. 2009, 4, 29-32.

5. Nedev P. Cranio-caudal transdomal sutures for the nasal tip correction. European Archives of Oto-Rhino-Laryngology and Head \& Neck, Volume 266, Number 2 / February, 2009, pp 1434-4726.

6. Goode RL. Surgery of the incompletent nasal valve. Laryngoscope. $1985 ; 95 ; 546-555$ рална ринопексия, имплантация на автогенен хрущял и сутурните техники.
7. Gunter JP, Rohrich RJ. Correction of the pinched nasal tip with alar spreader grafts. Plast Reconstr Surg 1992; 90: 821.

8. Toriumi DM, Josen J, Weinberger M, Tardy ME Jr. Use of alar batten grafts for correction of nasal valve collapse. Arch Otolaryngol Head Neck Surg. 1997; 123: 802-808.

9. Sheen JH. Spreader graft: A method of reconstructing the roof of the middle nasal vault following rhinoplasty. Plast Reconstr Surg 1984; 73: 230-239.

10. Hommerich C.P. The Lateral Rhinopexy.Results of an Alternative Technique to Treat Nasal Valve Collapse. Otorhinolaryngol Nova. 2001; 11: $162-167$.

11. Kalan F.R.C.S. (Orl-Hns) a1, G. S. Kenyon B.Sc., M.B.A., M.D., F.R.C.S., F.R.C.S. (Ed) a1 and T. A. R. Seemungal M.R.C.P. a1 Treatment of external nasal valve (alar rim) collapse with an alar strut. Journal of Laryngology \& Otology (2001), 115: 788-791.

Адрес за кореспонденция:

\author{
Варна 9010 \\ бул. „Хр. Смирненски“ 1 \\ УМБАЛ „Св. Марина“-Клиника по УНГ-болести \\ drnedev@abv.bg
}

